Supporting Information for

\title{
Comprehensive Composition, Structure and Size Characterization for Thiophene Compounds in Petroleum Using Ultrahigh Resolution Mass Spectrometry and Trapped Ion Mobility Spectrometry
}

\author{
Yanfen Zhang1, a, Yehua Han*,1, a, Jianxun $\mathrm{Wu}^{\mathrm{a}}$, Yinghao \\ Wang ${ }^{\mathrm{a}}$, Jiayi $\mathrm{Li}^{\mathrm{a}}$, Quan Shi ${ }^{\mathrm{a}}$, Chunming Xu' ${ }^{\mathrm{a}}$, Chang Samuel Hsu ${ }^{\mathrm{a}}$ b \\ a State Key Laboratory of Heavy Oil Processing, China University of Petroleum-Beijing 102249, \\ P. R. China \\ b (i) Department of Chemical and Biomedical Engineering, Florida A\&M University/Florida \\ State University, Tallahassee, FL 32310 USA (ii) Petro Bio Oil Consulting, Tallahassee, FL \\ 32312 USA \\ *Correspondence: Dr. Yehua Han, E-mail: hanyehua@cup.edu.cn \\ ${ }^{1}$ The two authors contributed equally to this work.
}

\section{Table of Contents}

GC-SCD and GC-MS Analysis

Principle of TIMS Analysis .

Proposed Ionization Mechanisms ....... . .53

Supporting Table and Figures. .55

Reference

S12 
GC-SCD and GC-MS Analysis. Agilent 7890A GC equipped with a HP-5 MS column (30 m $\times$ $0.25 \mathrm{~mm} \times 0.25 \mu \mathrm{m}$ ) and a SCD detector (Agilent, 355) was used for GC-SCD analysis. The column oven for diesel started at $40{ }^{\circ} \mathrm{C} / \mathrm{min}$ and followed by a ramp of $4{ }^{\circ} \mathrm{C} / \mathrm{min}$ to $250{ }^{\circ} \mathrm{C}$, then ended at $300{ }^{\circ} \mathrm{C}$ by a ramp of $10{ }^{\circ} \mathrm{C} / \mathrm{min}$. The temperature was kept at $300{ }^{\circ} \mathrm{C}$ for $20 \mathrm{~min}$. When it came to crude oil, the start temperature was changed from $40{ }^{\circ} \mathrm{C}$ to $80{ }^{\circ} \mathrm{C} / \mathrm{min}$. The end temperature was kept at $300{ }^{\circ} \mathrm{C}$ and held for $20 \mathrm{~min}$.

The GC-MS analysis was carried out on an Agilent 7890 gas chromatography equipped with a HP-5 MS $(60 \mathrm{~m} \times 0.25 \mathrm{~mm} \times 0.25 \mu \mathrm{m})$ fused silica capillary column. For diesel, the oven temperature was set at $50^{\circ} \mathrm{C}$ for $1 \mathrm{~min}$ and heated at $20^{\circ} \mathrm{C} / \mathrm{min}$ to $120^{\circ} \mathrm{C}$, followed by a ramp of $4{ }^{\circ} \mathrm{C} / \mathrm{min}$ to $250^{\circ} \mathrm{C}$, and then heated to $310^{\circ} \mathrm{C}$ with the ramp of $3{ }^{\circ} \mathrm{C} / \mathrm{min}$. The temperature of $310^{\circ} \mathrm{C}$ was held constant for $10 \mathrm{~min}$. In case of crude oil, the started oven temperature was set at $80^{\circ} \mathrm{C}$ for 2 min and heated to $310^{\circ} \mathrm{C}$.

Principle of TIMS Analysis. Gas phase separation of compounds was performed on TIMS using electric field force and gas force after ionization in the APCI source. The principle of TIMS is that ions travel through the analyzer under the control of an electric field and a moving gas. The shape, configuration, and charge state of the trapped ion, as well as the temperature, pressure, composition and polarizability of the drift gas jointly determine the mobility value of the ion, $K . K$ is conveniently expressed as $K_{0}$ under standard conditions. The mobility values given by the instrument as $1 / K_{0}$ has a relationship with the collisional cross section (CCS) of the compounds, as below:

$$
\mathrm{CCS}=18500 \frac{z}{K_{0}} \sqrt{T \frac{M m}{M+m}}
$$


where $z$ is the charge on the ion, $K_{0}$ is a function of temperature, pressure and electric field, $T$ is absolute temperature, $M$ is the mass of the ion, and $m$ is the mass of collision gas. Detailed description about TIMS can be found elsewhere. ${ }^{1-2}$

Proposed Ionization Mechanisms. Ionization mechanisms for thiophene compounds in this work are proposed as follows, where $\mathrm{S}$ represents the solvent used, $\mathrm{M}$ represents the analyte, and $\mathrm{N}_{2}$ mainly comes from the sheath and auxiliary gas used in the APCI source.

$[\mathrm{M}]^{+} \bullet$ could be generated through charge exchange:

$$
\begin{aligned}
& \mathrm{N}_{2}+\mathrm{e}^{-} \rightarrow \mathrm{N}_{2}^{+\bullet}+2 \mathrm{e}^{-} \\
& \mathrm{N}_{2}^{+\bullet}+\mathrm{S} \rightarrow \mathrm{N}_{2}^{+\bullet}+\mathrm{S}^{+\bullet} \\
& \mathrm{M}+\mathrm{S}^{+\bullet} \rightarrow[\mathrm{M}]^{+\bullet}+\mathrm{S}
\end{aligned}
$$

$[\mathrm{M}+\mathrm{H}]^{+}$generated through proton transfer:

$$
\begin{aligned}
& \mathrm{S}^{+\bullet}+\mathrm{S} \rightarrow \mathrm{SH}^{+}+[\mathrm{S}-\mathrm{H}] \\
& \mathrm{M}+\mathrm{SH}^{+} \rightarrow[\mathrm{M}+\mathrm{H}]^{+}+\mathrm{S}
\end{aligned}
$$

$[\mathrm{M}-\mathrm{H}]^{+}$generated from the protonated analytes via elimination of a hydrogen molecule:

$$
[\mathrm{M}+\mathrm{H}]^{+} \rightarrow[\mathrm{M}-\mathrm{H}]^{+}+\mathrm{H}_{2}
$$

$[\mathrm{M}-\mathrm{H}]^{+}$generated from the $[\mathrm{M}]^{+}$by loss of hydrogen radical:

$$
[\mathrm{M}]^{+\bullet} \rightarrow[\mathrm{M}-\mathrm{H}]^{+}+\mathrm{H}^{\bullet}
$$

Oxidized protonated molecule was the most expected process for the formation of $[\mathrm{M}+\mathrm{OH}]^{+}$, the mechanisms could be: 


$$
\begin{gathered}
\mathrm{O}_{2} *+\mathrm{O}_{2} \rightarrow \mathrm{O}_{3}+\mathrm{O}, \text { where } \mathrm{O}_{2} * \text { is excited } \mathrm{O}_{2}, \\
{[\mathrm{M}+\mathrm{H}]^{+}+\mathrm{O}_{3} \rightarrow[\mathrm{M}+\mathrm{O}+\mathrm{H}]^{+}+\mathrm{O}_{2}}
\end{gathered}
$$

Since $\mathrm{H}_{2} \mathrm{O}$ adduct can be generated with the existence of residual water in instrument, ${ }^{35}$ the ionization mechanism for $[\mathrm{M}+\mathrm{OH}]^{+}$might also be:

$$
[\mathrm{M}-\mathrm{H}]^{+}+\mathrm{H}_{2} \mathrm{O} \rightarrow\left[\mathrm{M}-\mathrm{H}+\mathrm{H}_{2} \mathrm{O}\right]^{+}
$$




\section{Supporting Table and Figures}

Table S1. ${ }^{\text {TIMS }} \mathrm{CCS}_{\mathrm{N} 2}$ and $m / z$ of thiophene compounds corresponding to $\mathrm{DBE}=6$ and 9 from diesel and crude oil

\begin{tabular}{|c|c|c|c|}
\hline$m / z$ & DBE & $\mathrm{CCS}_{\mathrm{N} 2}\left(\AA^{2}\right.$, diesel $)$ & $\operatorname{CCS}_{\mathrm{N} 2}\left(\AA^{2}\right.$, crude oil $)$ \\
\hline 134.02 & 6 & 114.5 & 114.3 \\
\hline 148.03 & 6 & 117.6 & 117.5 \\
\hline 162.05 & 6 & 122.4 & 122.8 \\
\hline 176.07 & 6 & 127.5 & 127.6 \\
\hline 190.08 & 6 & 132.4 & 132.8 \\
\hline 204.10 & 6 & 139.0 & 138.6 \\
\hline 218.11 & 6 & 144.5 & 144.6 \\
\hline 232.13 & 6 & 151.3 & 150.8 \\
\hline 246.14 & 6 & 157.2 & 156.4 \\
\hline 260.16 & 6 & 162.4 & 162.1 \\
\hline 274.17 & 6 & 167.9 & 167.8 \\
\hline 288.19 & 6 & 173.8 & 174.8 \\
\hline 302.21 & 6 & 177.7 & 179.7 \\
\hline 316.22 & 6 & 182.9 & 184.8 \\
\hline 330.24 & 6 & 187.5 & 190.6 \\
\hline 344.25 & 6 & 191.8 & 194.9 \\
\hline 358.27 & 6 & 196.4 & 199.2 \\
\hline 184.03 & 9 & 127.1 & 127.2 \\
\hline 198.05 & 9 & 131.7 & 131.9 \\
\hline 212.07 & 9 & 136.6 & 136.6 \\
\hline 226.08 & 9 & 141.9 & 142.0 \\
\hline 240.10 & 9 & 147.9 & 148.1 \\
\hline 254.11 & 9 & 154.2 & 153.7 \\
\hline 268.13 & 9 & 160.2 & 159.6 \\
\hline 282.14 & 9 & 166.1 & 164.9 \\
\hline 296.16 & 9 & 170.4 & 170.2 \\
\hline 310.17 & 9 & 177.8 & 177.6 \\
\hline 324.19 & 9 & 183.7 & 182.4 \\
\hline 338.21 & 9 & 186.8 & 187.2 \\
\hline 352.22 & 9 & 187.9 & 192.9 \\
\hline
\end{tabular}



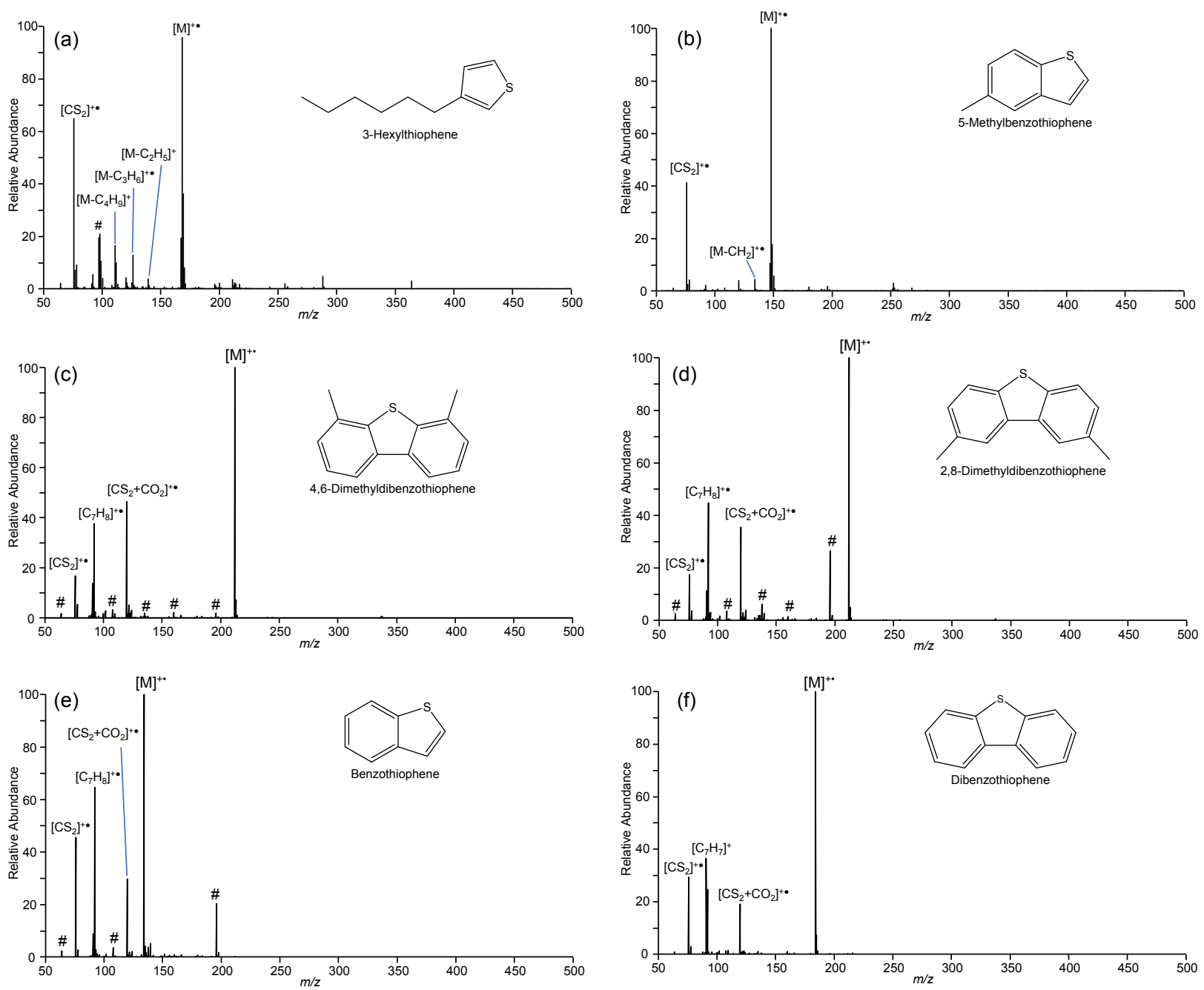

Figure S1. (+) APCI ultrahigh resolution mass spectra of the model thiophene compounds with $\mathrm{CS}_{2}$ as solvent. (a) 3Hexylthiophene, (b) 5-Methylbenzothiophene, (c) 4,6-Dimethyldibenzothiophene, (d) 2,8-

Dimethyldibenzothiophene, (e) Benzothiophene, and (f) Dibenzothiophene. Peaks with \# are from contaminants. It indicates that thiophene model compounds were mainly ionized as $[\mathrm{M}]^{+}$. 

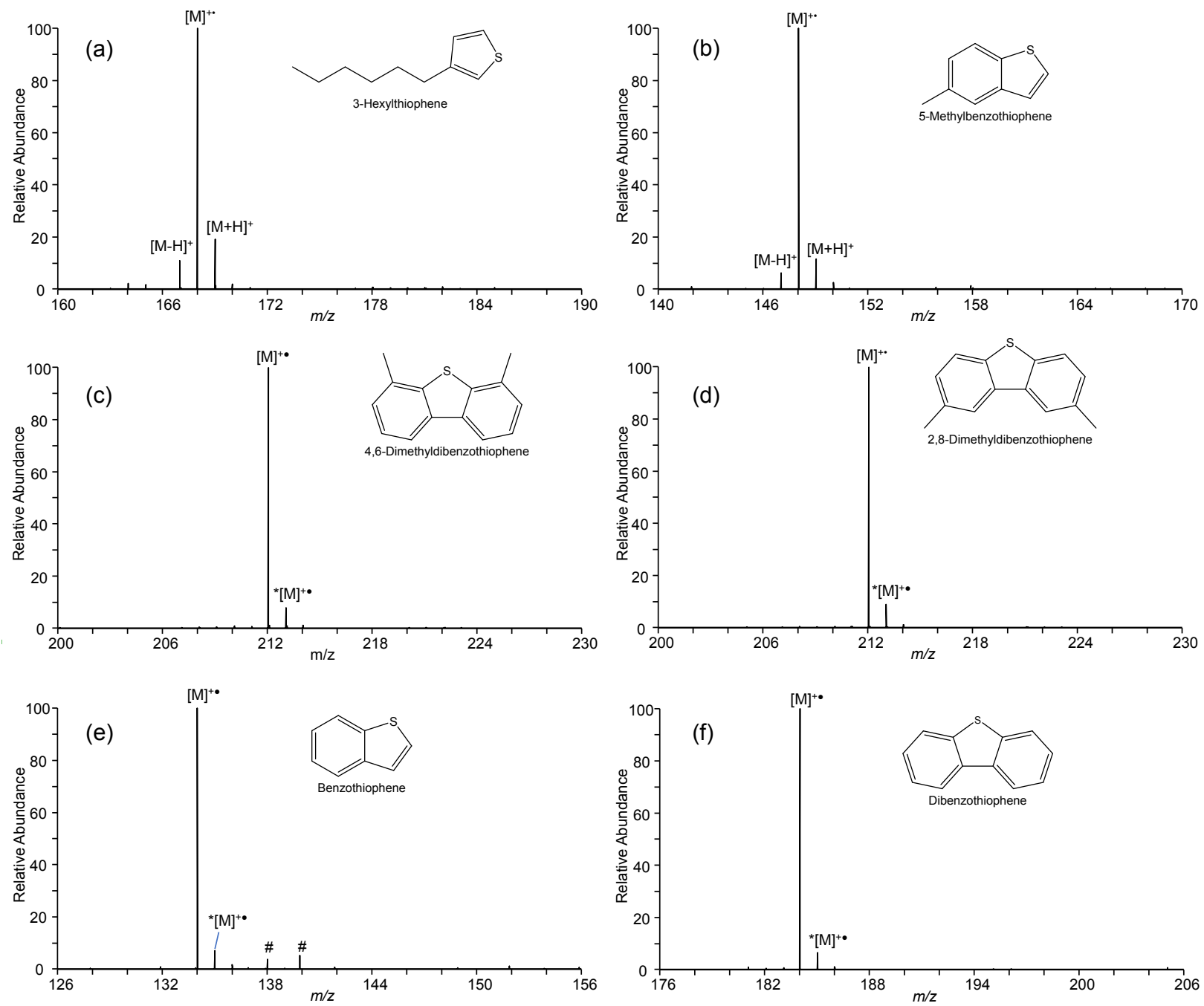

Figure S2. The expanded (+) APCI ultrahigh resolution mass spectra of the model thiophene compounds with $\mathrm{CS}_{2}$ as solvent. (a) 3-Hexylthiophene, (b) 5-Methylbenzothiophene, (c) 4,6-Dimethyldibenzothiophene, (d) 2,8-

Dimethyldibenzothiophene, (e) Benzothiophene, and (f) Dibenzothiophene. Peaks with \# are from contaminants. 

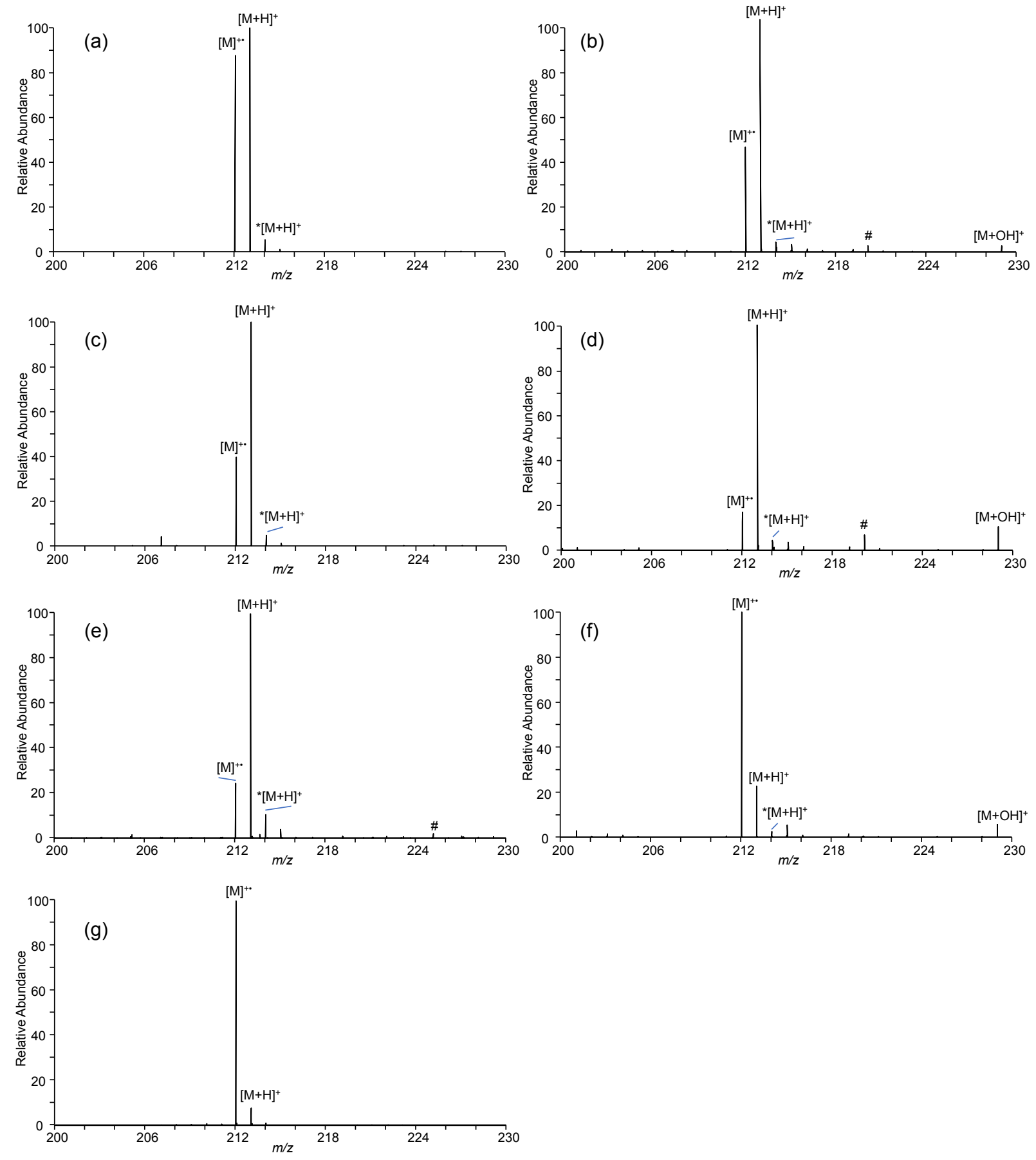

Figure S3. The expanded (+) APCI ultrahigh resolution mass spectra of 4,6-dimethyldibenzothiophene in various solvents: (a) toluene, (b) methanol, (c) cyclohexane, (d) pentane, (e) iso-octane, (f) acetonitrile, and (g) $\mathrm{CS}_{2}$. Peaks with an asterisk represent ions with one ${ }^{13} \mathrm{C}$. Peaks with \# are from contaminants. 

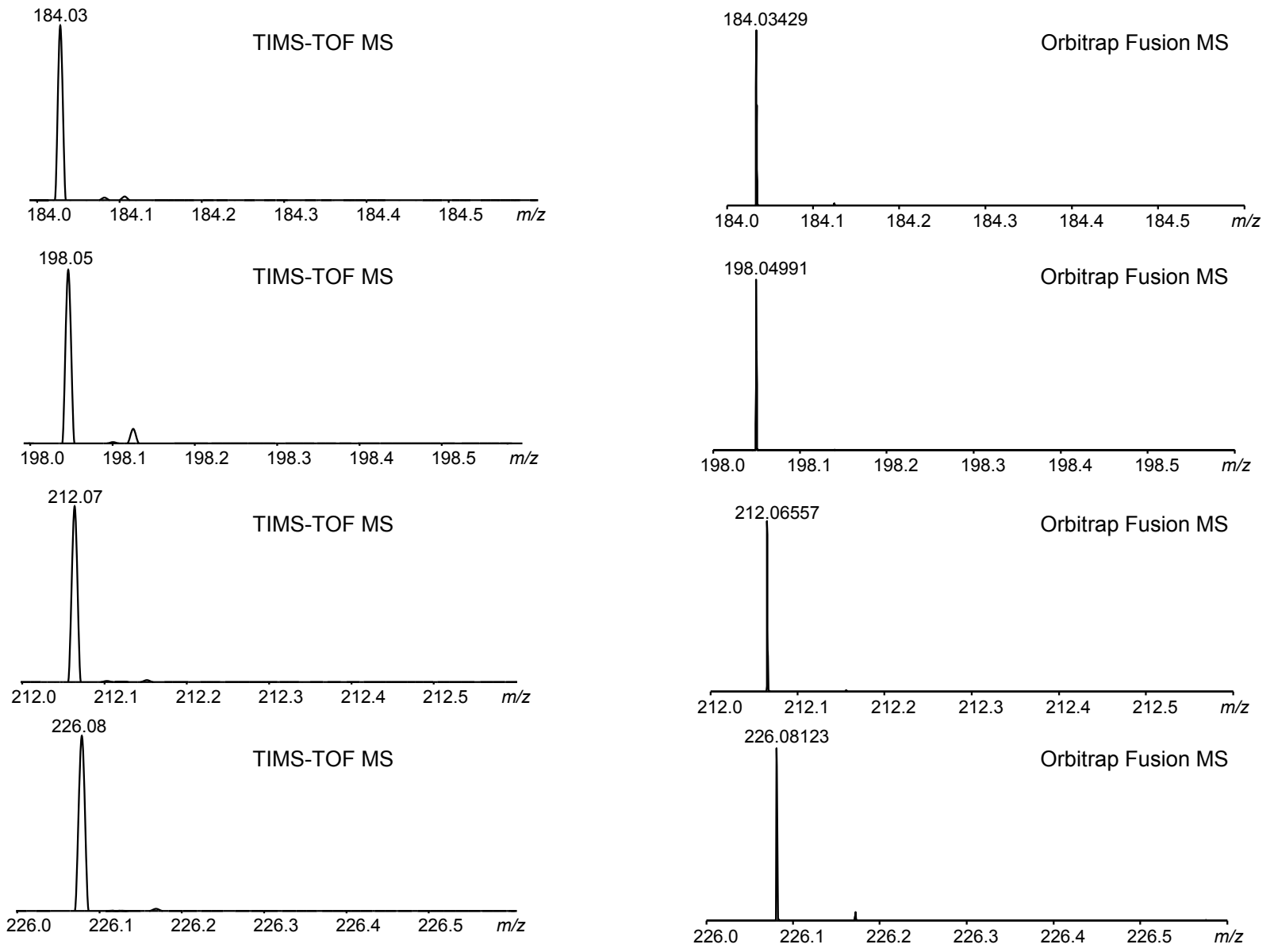

Figure S4. Mass scale-expanded segments of TIMS-TOF and Orbitrap Fusion mass spectra of nominal $\mathrm{m} / \mathrm{z}$ 184, 198, 212 and 226. Orbitrap Fusion MS showed no significant isobars in the mass range from which TIMS peaks were extracted, confirming that the species separated by IM were indeed isomers. 


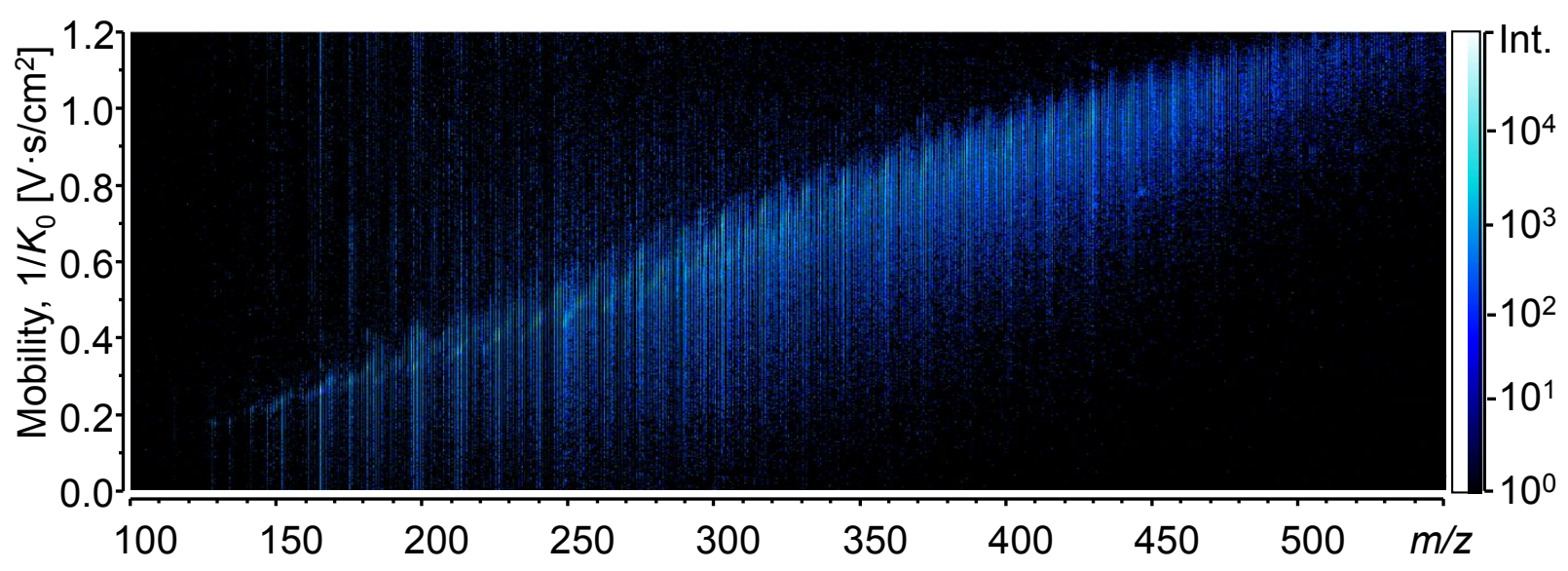

Figure S5. TIMS-TOF MS analysis heat map for thiophenes in crude oil.


Figure S6. (a) GC-SCD chromatogram of the separated thiophene fraction from diesel oil; (b) GC-MS total ion chromatogram of the separated thiophene fraction from diesel oil; (c)-(e) GC-MS selective ion chromatograms at $m / z=184,198,212$ of the thiophene fraction, respectively. 


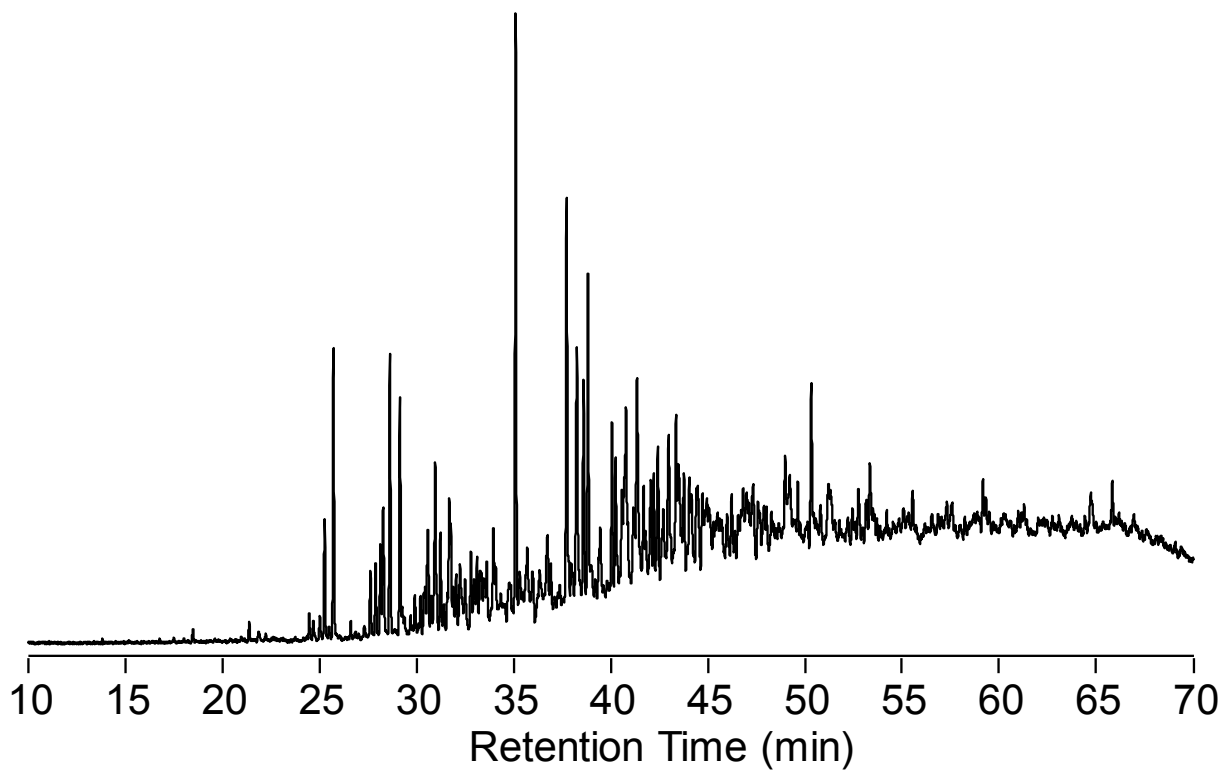

Figure S7. GC-SCD chromatogram of the separated thiophene fraction from crude oil. 


\section{Reference}

(1) Hernandez, D. R.; DeBord, J. D.; Ridgeway, M. E.; Kaplan, D. A.; Park, M. A.; FernandezLima, F., Ion dynamics in a trapped ion mobility spectrometer. Analyst 2014, 139, 1913-1921.

(2) Ridgeway, M. E.; Lubeck, M.; Jordens, J.; Mann, M.; Park, M. A., Trapped ion mobility spectrometry: A short reviewMark. Int. J. Mass Spectr. 2018, 425, 22-35. 